\title{
Development of Battery Powered Manually Operated Device for Guava Harvesting
}

\author{
C.S. Matholiya ${ }^{1 *}$, A.L. Vadher $^{1}$, S.K. Jain ${ }^{2}$ and M.J. Nayaka ${ }^{1}$ \\ ${ }^{1}$ Department of Farm Machinery and Power Engineering, CAET, JAU, Junagadh, India \\ ${ }^{2}$ Department of Farm Structures, CAET, DBSKKV, Dapoli, India \\ *Corresponding author:
}

\section{A B S T R A C T}

\begin{tabular}{|l|}
\hline K e y w o r d s \\
Battery powered \\
device, \\
Guava harvesting, \\
Handle grips
\end{tabular}

\begin{abstract}
India is the leading guava producer in the world today. The traditional harvesting method (manual picking) of guava fruit is a labour intensive, tedious, time consuming as well as risk involved process. Due to declining labour availability, risky operation, time consuming and increasing labour cost combined with more awareness to health and safety issues, it is mandatory mechanize the fruit harvesting operation. Therefore, was necessary to develop device that should be simple, power operated, easy assemble and disassemble, low cost and light in weight with a proper balance. Considering this facts, a battery powered harvesting device with rotating serrated blade cutting mechanism was fabricated at Tansa Farm, ASPEE Agricultural Research and Development Foundation, Mumbai. Battery powered guava harvesting device consists three different portions namely upper portion, middle portion and lower portion. The main parts of the device were harvesting frame, supporting pipe, connector, conveyor, cutting mechanism, rectangular box and handle grips. One single operator can easily harvest the guava fruit with complete safety.
\end{abstract}

\section{Introduction}

Guava is the fourth most important fruit in terms of area and production after mango, banana and citrus. In India, fruits are cultivated on 6480 thousand hectares of land, production is about 92846 thousand metric ton and productivity is about 14.33 metric ton per hectare. Guava is an important fruit crop of subtropical countries. Guava is cultivated on 261.4 thousand hectares of land, production is about 3648.2 thousand metric ton and productivity is about 13.9 metric ton per hectare (HSD, 2017). In India, Guava production is getting increased day by day with its increasing demand. In harvesting of guava fruits, ripening of guava fruits are not uniform and they needs number of pickings. Guava fruits are highly perishable and sensitive so that they easily get damaged even if there is a small impact or hitting force.

In Tansa Farm ASPEE ARDF, Guava fruit harvesting is commonly handpicked. Manual harvesting of guava fruit is comparatively time consuming, tedious, more laborious and risky 
during harvesting seasons. However, in India due to the smaller size of farm and ongoing cropping systems, it allows us only to develop the effective manual harvesting devices for horticultural fruits. In case of guava harvesting, manual harvesters used for harvesting mango itself is found to be appropriate and being used. Considering these facts and economic condition of our farmers there is a need to develop a low cost, light weight and simple device for harvesting guava fruit so that it can maximize the working capacity of labour, increase the capacity and harvesting of guava fruits along with minimizing the harvesting losses.

Siwalak et al., (1989) developed a hand held single fruit harvesting device and a mango stem picker. The single fruit harvester was circular in shape and equipped with a cutter bar, which was actuated by a hand grip bicycle brake cable. The handle bar was made of aluminium pipe of $2.84 \mathrm{~cm}$ (1.125 inch) diameter. The weight of the device was $1.6 \mathrm{~kg}$ and harvested singe fruit at a time. In test runs the hourly harvests for avocado, king orange and mango were 300, 276, and 452 fruit respectively. The mango stem picker consists of a $13 \mathrm{~cm}$ diameter circular wire frame and 10 wire teeth in the form of an inverted ' $U$ ' around the edges of the frame. The wire frame also supports a cloth pouch. The device is attached to a $2-4 \mathrm{~m}$ long bamboo pole with an unloading mechanism. The device is capable of harvesting 5 - 6 fruit at a time or about 486 fruits per hour, without damage or bruising of the fruit.

A mango harvester known as "Nutan Nipper" developed at KKV, Dapoli, Maharashtra was tested for harvesting of mango fruit. The device harvested all the fruits with peduncle avoiding injury to the fruits. It avoided jerks to the branches and hence, no loss by way of fruits drop from the tree was observed. It avoided shaking of branches and thus no mechanical injury to the branch of mango tree was observed. The device was reported to be simple and very handy because it could be operated by one person. It could harvest 140 fruits/h (Anon., 1994).

An improved mango harvester similar to Dapoli harvester was designed and developed at IARI, Delhi. It was simple manually operated tool designed to harvest the fruits at different height and could be used for harvesting mango, guava and citrus fruit. The device was capable of cutting the stem of fruit of 3-4 mm diameter from a height of 15 feet. It could harvest Dashehari mango at rate of 38 $\mathrm{kg} / \mathrm{hr}$. The equipment consisted of cutting blade, flexible cable with hand lever, conduit pipe and collection basket. Two horizontal blade made of high carbon steel with serrations were mounted on a mechanism which was operated with the help of flexible cable and hand lever. One end of the cable was connected to the cutting mechanism and the other end to the hand lever. A conduit pipe of $3000 \mathrm{~mm}$ long and $20 \mathrm{~mm}$ outer diameter was used for mounting the cutting mechanism and hand lever. A collecting basket of $3 \mathrm{~mm}$ diameter GI wire frame and woven nylon net was mounted on conduit pipe (Anon., 1996).

Valdez (1999) developed a mango fruit harvester to minimize damage and to make harvesting operation easy. The harvester consists of a $6 \mathrm{~m}$ pole that could be adjusted depending on the height of the fruit to be harvested. The upper pole is $12 \mathrm{~mm}$ in diameter and $3 \mathrm{~m}$ in length while the lower pole is $19 \mathrm{~mm}$ in diameter and $3 \mathrm{~m}$ in length. The upper pole is fitted inside the lower pole and can be adjusted to desired length. A harvester ring, a basket, and a stripper are attached at the end portion of upper pole. Field test revealed that a person using a designed harvester could gather 480 - 540 fruits/hour. Existing harvesters have a capacity of 380 400 fruits/hour. The harvester gave about 95 
undamaged per 100 fruits while existing harvester gave 84 undamaged per 100 fruits harvested.

Hamam et al., (2011) developed peach electrical picking hook which was consisted of a telescopic carrier of two hollow aluminium pipes $3 \mathrm{~m}$ in length. The upper one $\left(\emptyset_{1}\right.$ $=16 \mathrm{~mm})$ is inserted into the lower one $\left(\varnothing_{2}\right.$ $=20 \mathrm{~mm}$ ) to adjust the height of peach electrical picking hook. Picking mechanism consists of a linear $12 \mathrm{~V} \mathrm{DC}$ motor, hook shaft, retrain spring, picker shaft guide and picker hook. The DC motor is fixed on the upper end of the telescopic carrier, while the hook shaft is fixed inside the magnetic coil of the DC motor to create magnetic field suitable for attracting down the hook shaft after connecting the direct current to it. Fruits collecting mechanism consists of fruit receiving/transporting tube and fruit collecting basket. The upper end of fruits receiving tube $(\varnothing=25 \mathrm{~cm})$ is fixed on the telescopic carrier under the picker hook with about $20 \mathrm{~cm}$ to receive and transport the picked fruits to the mobile fruit collecting basket. DC source and operation circuit, a battery was used as DC source to operate the linear DC motor through electrical wires passing inside pipes of telescopic carrier, while the operation switch was fixed on the lower pipe of the telescopic carrier in a suit place for operator hand. The picker productivity using electrical picking hook was increased by about 91.32, 146.92, and $46.30 \%$ and saving the total harvesting cost by about $47.73,62.29$ and $41.38 \%$ (as an average percentages) comparing with electrical picking holder, manual picking hook and hand picking method, respectively for picking Meet Ghamr and Early Grand peach fruits varieties.

Nakum et al., (2018) designed and developed a battery operated mango harvester. It consisted of conveyor, $12 \mathrm{~V}$ DC battery, DC motor (high speed), GI blade, camera, display and switch. A camera having 2 MP high resolution with 7 inch display was mounted on device for ease of cutting operation. Efficiency of the developed harvesting device was observed 350 fruits/hr which was very high as compared to manual picking.

\section{Materials and Methods}

The methodology was used for the development of battery powered harvesting device for guava fruit as follow.

\section{General considerations}

As a part of general consideration following physical properties of guava fruit, guava peduncles, guava stem and plant parameters were taken into account for the development of battery powered harvesting device for guava fruit.

\section{Guava fruit}

An average equivalent diameter of ripe guava fruit was found as63.77 $\mathrm{mm}$ using average values of length, breadth and thickness of guava fruit and it were measured using digital vernier caliper. An average value of weight of single fruit was obtained143.01g. Based on visual observation the shape and colour observed were accordingly round to ovate and dark green to yellowish green.

\section{Guava peduncle and guava stem}

Physical properties of guava peduncle and stem were used for design of cutting mechanism of harvesting device. Guava fruits are required to cut with peduncle as well as stem. Generally guava fruits were cut with peduncle but sometimes it cuts with stem along with one or two leaves. An average value of diameter of guava peduncle and stem were obtained accordingly $2.36 \mathrm{~mm}$ and 3.2 $\mathrm{mm}$. Cutting strength of guava peduncle and stem were used to design of circular serrated cutting blade of harvesting device. Warner- 
Bratzler Blade with Rectangular Hole probe was used to measure cutting strength of guava peduncle and stem. An average value of cutting strength of guava peduncle and stem were obtained accordingly $137.401 \mathrm{~N}$ and 276.556 N. An average value of cutting stress of guava peduncle and stem were obtained accordingly $33.570 \mathrm{~N} / \mathrm{mm}^{2}$ and $41.322 \mathrm{~N} / \mathrm{mm}^{2}$. An average value of cutting torque of guava peduncle and stem were obtained accordingly $0.325 \mathrm{~N} \mathrm{~m}$ and $0.886 \mathrm{~N} \mathrm{~m}$.

\section{Guava plant parameters}

An average distance between row to row and plant to plant was found accordingly $5.09 \mathrm{~m}$ and $2.27 \mathrm{~m}$. An average height of plant was found $3.825 \mathrm{~m}$. An average value of plant canopy diameter was found $4.94 \mathrm{~m}$. An average value of plant canopy volume of guava plant was obtained $24.78 \mathrm{~m}^{3}$.

\section{Development of guava harvesting device}

The manual picking of guava fruit is done by simply removing fruits from the plant and putting them into a suitable container. Harvesting of fruit can be done at appropriate maturity. Guava fruit should be harvested, when fruit attained dark green to greenish yellow colour. To minimize the damage, it is desirable to harvest the fruits with the stalk along with one or two leaves. This is very time consuming, tedious and more labour is required during harvesting season. Keeping in view that, the harvesting device was developed such that pulling of fruits towards the operator be not needed to detach the fruit from the plant but the stem or peduncle be cut by means of circular serrated cutting blade. The blades was operated by a battery powered DC motor. Motor was operated by on/off operating switch which was fitted and located onto lower supporting pipe. Two supporting pipes were used which were connected with the help of jointer. Harvesting frame with conveyor was attached at top of the upper supporting pipe while handle grips and operating switch were located onto lower supporting pipe. Plastic rectangular box with battery was attached at the end of lower supporting pipe with the help of clamp. Also the separated / detached fruit is conveyed to the ground through a conveyor one by one. Front view, side view and conceptual view of the developed harvesting device are shown in Figure 1 - 6.

\section{Main parts of the developed harvesting device}

\section{Harvesting frame}

A harvesting frame was made by hollow steel tube having $8 \mathrm{~mm}$ outer diameter, $7.2 \mathrm{~mm}$ inner diameter, $0.8 \mathrm{~mm}$ thickness, $355 \mathrm{~mm}$ length and $260 \mathrm{~mm}$ width. Total periphery of harvesting frame was $1030 \mathrm{~mm}$. Shape of the harvesting frame was oval. In the harvesting frame the cutting blade can cut the fruits at $360^{\circ}$ around its periphery as shown in Figure 7. Guava fruits were required to cut an around $360^{\circ}$ angle along with harvesting frame. So harvesting frame was fabricated for harvesting of guava fruit at $360^{\circ}$ angle. Peduncle or stem of the fruit should be viewed while fruit harvesting by battery powered motor operated circular blade so lower end of harvesting frame was welded with connector at $10^{\circ}$ angle for connecting with supporting pipe as shown in Figure 9. $10^{\circ}$ angle was required for proper alignment of cutting mechanism with stem or peduncle of guava fruit. Front view and side view of the drawing of harvesting frame are shown in Figure 8 and 9. Front view and side view of the harvesting frame are shown in Figure 10.

\section{Supporting pipe}

Two different length $(1827 \mathrm{~mm}+1503 \mathrm{~mm})$ and same diameter aluminium pipes were used which were easily available in local market. Upper pipe was used to attach harvesting 
frame and lower pipe was used for operating mechanism, handling and battery hanging position. Reason for using two pipes was used that easy to transport from one place to other place, easy to dissemble while it is not in use and easy to assemble while it is in use. Connector was used for connecting the supporting pipe with harvesting frame. Jointer was used to join two different length of supporting pipe. The supporting pipe is shown in Figure 11. Jointer and connector are shown in Figure 12.

\section{Cutting mechanism}

Circular serrated cutting blade having 100 number of teeth and $102 \mathrm{~mm}$ diameter was used as a cutting mechanism in the device which was operated by DC motor.

\section{Circular serrated cutting blade}

Circular serrated cutting blade was used made of high carbon steel having $102 \mathrm{~mm}$ diameter, $0.8 \mathrm{~mm}$ thickness and 100 number of teeth. The function of the blade was cut the peduncle and stem of fruit with minimize mechanical and other losses. Cutting blade was rotated in circular motion. It was got power from battery operated motor which was mounted on back side of blade and fixed with harvesting frame as shown in Figure 13.

\section{Motor}

Motor was the only source of power to rotate the cutting blade. Motor was fixed with harvesting frame by means of two screw as shown in Figure 14. Motor got power from battery which was fixed at the lower end of supporting pipe placed into rectangular box.

\section{Measurement of speed of motor}

Speed of motor was measured with the help of digital photo type tachometer instrument. Stick the cut-off a length of 12 to $25 \mathrm{~mm}$ of reflective tape as near as possible to the outer edge of rotating object (disc or shaft) as shown in Figure 15. The tachometer was tested and calibrated at a distance of 100 to $300 \mathrm{~mm}$ (target to photo probe).. The photo probe was directed at an angle of $\pm 30^{\circ}$ and the visible light beam was aligned with applied target (Reflective tape). Speed of motor with Noload rating was observed as $6174 \mathrm{rpm}$ and with load rating as $3197 \mathrm{rpm}$. Peripheral speed of circular serrated cutting blade was found $17.07 \mathrm{~m} / \mathrm{s}$.

$$
\begin{aligned}
\text { Peripheral speed }(\mathrm{m} / \mathrm{s}) & =\pi \mathrm{DN} \quad \ldots . .(1) \\
& =3.14 \times 0.102 \times 3197 \\
& =1023.94 / 60 \\
& =17.07 \mathrm{~m} / \mathrm{s}
\end{aligned}
$$

\section{Torque of motor}

Torque of the motor was determined by observing the speed using tachometer and considering the power of the motor using the following formula,

$\mathrm{P}=\frac{2 \pi \mathrm{NT}}{60}$

Where,

Power $(\mathrm{P})=370 \mathrm{~W}(0.5 \mathrm{HP})$

Speed of motor with load rating (with blade) $\mathrm{N}=3197 \mathrm{rpm}$

Torque of motor $(\mathrm{Nm}) \mathrm{T}=$ ?

Torque of motor $=\frac{60 \times \mathrm{P}}{2 \pi \mathrm{N}}$.

Torque of motor $=\frac{60 \times 370}{2 \times 3.14 \times 3197}$

$$
\text { Torque of motor }=\frac{22200}{20077.16}
$$

Torque of motor $(\mathrm{T})=1.106 \mathrm{~N} \mathrm{~m}$ 
Table.1 Weight distribution of the developed harvesting device

\begin{tabular}{|c|c|c|c|}
\hline Portion & Parts of device & Weight (g) & Portion wise weight (g) \\
\hline \multirow{4}{*}{ Upper Portion } & Harvesting Frame & 297 & \multirow{4}{*}{ 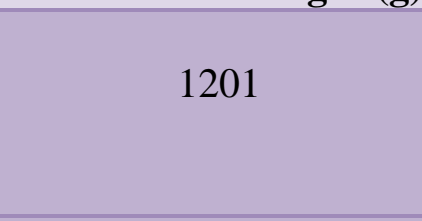 } \\
\hline & Conveyor & 428 & \\
\hline & Motor & 350.5 & \\
\hline & Blade + Blade holder & 125.5 & \\
\hline \multirow{5}{*}{$\begin{array}{l}\text { Middle } \\
\text { Portion }\end{array}$} & Supporting rod & 826.5 & \multirow{5}{*}{1046} \\
\hline & Electric Wire & 102 & \\
\hline & Operating Switch & 12.5 & \\
\hline & Handle grip & 11 & \\
\hline & Nut, bolt and jointer & 94 & \\
\hline \multirow[t]{2}{*}{ Lower Portion } & Battery & 535.5 & \multirow[t]{2}{*}{830.5} \\
\hline & $\begin{array}{l}\text { Rectangular Box with } \\
\text { clamp }\end{array}$ & 295 & \\
\hline \multicolumn{3}{|c|}{ Total weight } & 3077.5 \\
\hline
\end{tabular}

Table.2 Specifications of the developed guava harvesting device

\begin{tabular}{|c|c|c|}
\hline $\begin{array}{l}\text { Sr. } \\
\text { No. }\end{array}$ & Particulars & Specifications \\
\hline 1 & Name of the device & Developed harvesting device \\
\hline \multirow[t]{4}{*}{2} & \multicolumn{2}{|l|}{ Overall dimensions } \\
\hline & Length $(\mathrm{mm})$ & 3685 \\
\hline & Width (mm) & 260 \\
\hline & Total weight $(\mathrm{g})$ & 3077.5 \\
\hline \multirow[t]{11}{*}{3} & \multicolumn{2}{|l|}{ Harvesting frame ( Hollow steel tube) } \\
\hline & Length $(\mathrm{mm})$ & 355 \\
\hline & Width (mm) & 260 \\
\hline & Outer diameter $(\mathrm{mm})$ & 8 \\
\hline & Inner diameter (mm) & 7.2 \\
\hline & Thickness (mm) & 0.8 \\
\hline & Total periphery (mm) & 1030 \\
\hline & Angle of frame with supporting pipe (Degree) & 10 \\
\hline & Shape & Oval \\
\hline & Material & Hollow steel tube \\
\hline & Weight $(\mathrm{g})$ & 297 \\
\hline \multirow[t]{7}{*}{4} & \multicolumn{2}{|l|}{ Supporting pipe (hollow aluminium pipe) } \\
\hline & Overall length $(\mathrm{mm})$ & 3330 \\
\hline & Upper pipe length (mm) & 1827 \\
\hline & Lower pipe length (mm) & 1503 \\
\hline & Outer diameter $(\mathrm{mm})$ & 25 \\
\hline & Inner diameter $(\mathrm{mm})$ & 24 \\
\hline & Thickness (mm) & 1 \\
\hline
\end{tabular}




\begin{tabular}{|c|c|c|}
\hline & Shape & Circular (hollow) \\
\hline & Material & Aluminium \\
\hline & Weight $(\mathrm{g})$ & 826.5 \\
\hline \multirow[t]{6}{*}{5} & Connector & \\
\hline & Length (mm) & 50 \\
\hline & Outer diameter (mm) & 22 \\
\hline & Inner diameter $(\mathrm{mm})$ & 19 \\
\hline & Thickness (mm) & 3 \\
\hline & Shape & Circular (hollow) \\
\hline \multirow[t]{9}{*}{6} & Nut, bolt and Jointer & \\
\hline & Length of jointer (mm) & 65 \\
\hline & Diameter of jointer (mm) & 23 \\
\hline & Thickness of jointer (mm) & 3 \\
\hline & Material & Iron strip \\
\hline & Total nut and bolt (No.) & 3 \\
\hline & No. of hole & 3 \\
\hline & Diameter of hole (mm) & 8 \\
\hline & Total weight of nut, bolt and jointer (g) & 94 \\
\hline \multirow[t]{8}{*}{7} & Circular serrated cutting blade & \\
\hline & Diameter(mm) & 102 \\
\hline & Thickness(mm) & 0.8 \\
\hline & No. of Teeth & 100 \\
\hline & Speed of Blade $(\mathrm{m} / \mathrm{s})$ & 17.07 \\
\hline & Shape of Blade & Circular \\
\hline & Material & High carbon steel \\
\hline & Weight $(\mathrm{g})$ & 41.5 \\
\hline \multirow[t]{6}{*}{8} & Blade holder & \\
\hline & Length (mm) & 32 \\
\hline & Diameter $(\mathrm{mm})$ & 35 \\
\hline & Material & Iron strip \\
\hline & Weight $(\mathrm{g})$ & 84 \\
\hline & No. of screw & 1 \\
\hline \multirow[t]{11}{*}{9} & Motor & \\
\hline & Type & DC Motor \\
\hline & Speed with load rating (rpm) & 3197 \\
\hline & Speed with no-load rating (rpm) & 6174 \\
\hline & Power (W) & 370 \\
\hline & Power (HP) & 0.5 \\
\hline & Torque & 1.106 \\
\hline & Length(mm) & 70 \\
\hline & Diameter(mm) & 40 \\
\hline & Weight $(\mathrm{g})$ & 350.5 \\
\hline & No. of screw & 2 \\
\hline \multirow[t]{4}{*}{10} & Handle grip (high density foam grip) & \\
\hline & Length $(\mathrm{mm})$ & 100 \\
\hline & Diameter $(\mathrm{mm})$ & 35 \\
\hline & Thickness $(\mathrm{mm})$ & 5 \\
\hline
\end{tabular}




\begin{tabular}{|c|c|c|}
\hline & No. of grip & 2 \\
\hline & Material & High density foam \\
\hline & Weight $(\mathrm{g})$ & 11 \\
\hline \multirow[t]{11}{*}{11} & \multicolumn{2}{|l|}{ Battery } \\
\hline & Length (mm) & 97 \\
\hline & Width (mm) & 43 \\
\hline & Height (mm) & 51 \\
\hline & Voltage (V) & 12 \\
\hline & Ampere hour $(\mathrm{Ah})$ & 1.3 \\
\hline & $\begin{array}{l}\text { Total charging time required in lab (from fully discharged to } \\
\text { get fully charged) (min) }\end{array}$ & 35 \\
\hline & $\begin{array}{l}\text { Total discharge time required in lab (from fully charged to get } \\
\text { fully discharged while continue operating motor with blade) } \\
\text { (h) }\end{array}$ & 7.42 \\
\hline & $\begin{array}{l}\text { Number of working days in field (from fully charged to get } \\
\text { fully discharged if operate motor with blade during harvesting } \\
\text { in } 3 \text { h/day) (day) }\end{array}$ & 05 \\
\hline & $\begin{array}{l}\text { Total discharge time required in field (from fully charged to } \\
\text { get fully discharged if operate motor with blade during } \\
\text { harvesting) (h) }\end{array}$ & 15 \\
\hline & Weight $(\mathrm{g})$ & 535.5 \\
\hline \multirow[t]{6}{*}{12} & \multicolumn{2}{|l|}{ Rectangular box with clamp } \\
\hline & Length of box $(\mathrm{mm})$ & 225 \\
\hline & Width of box (mm) & 145 \\
\hline & Height of box (mm) & 80 \\
\hline & Material & Plastic \\
\hline & Weight $(g)$ & 295 \\
\hline \multirow[t]{7}{*}{13} & \multicolumn{2}{|l|}{ On/off switch (operating switch) } \\
\hline & Type & On/off switch \\
\hline & Length (mm) & 31 \\
\hline & Width (mm) & 16 \\
\hline & Height (mm) & 22 \\
\hline & Material & Plastic \\
\hline & Weight (g) & 12.5 \\
\hline \multirow[t]{6}{*}{14} & \multicolumn{2}{|l|}{ Conveyor } \\
\hline & Total length (mm) & 3860 \\
\hline & Diameter at the top $(\mathrm{mm})$ & 450 \\
\hline & Diameter at the bottom (mm) & 210 \\
\hline & Conveyor material & Cotton cloth (Boro) \\
\hline & Weight $(g)$ & 428 \\
\hline \multirow[t]{3}{*}{15} & \multicolumn{2}{|l|}{ Electric Wire } \\
\hline & Total length (mm) & 3800 \\
\hline & Weight $(\mathrm{g})$ & 102 \\
\hline
\end{tabular}


Fig.1 Front view of the drawing of the developed harvesting device

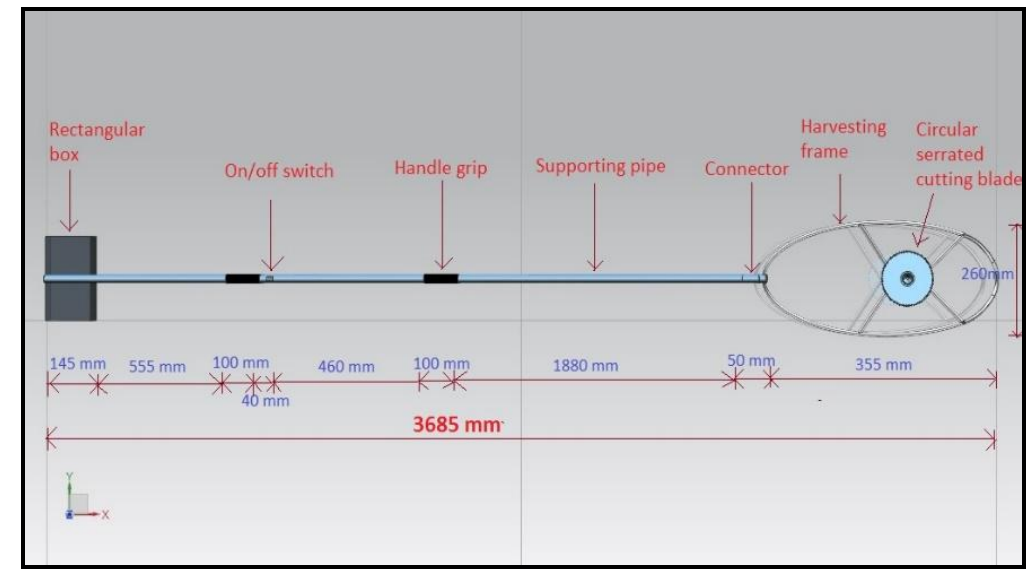

Fig.2 Front view of the developed harvesting device

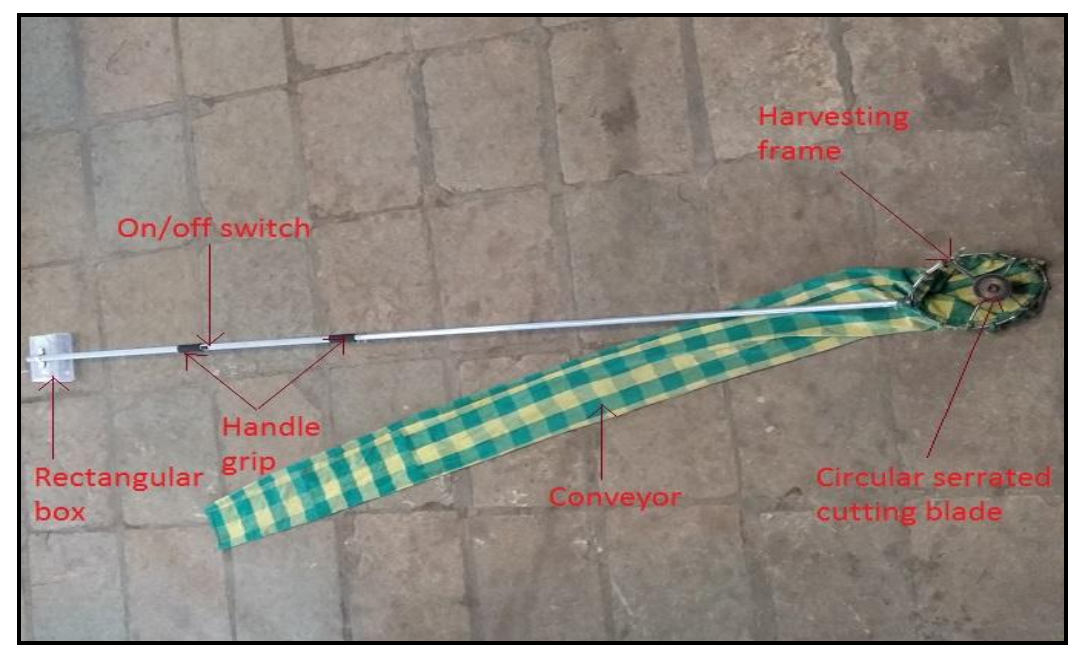

Fig.3 Front view of the drawing of the developed harvesting device

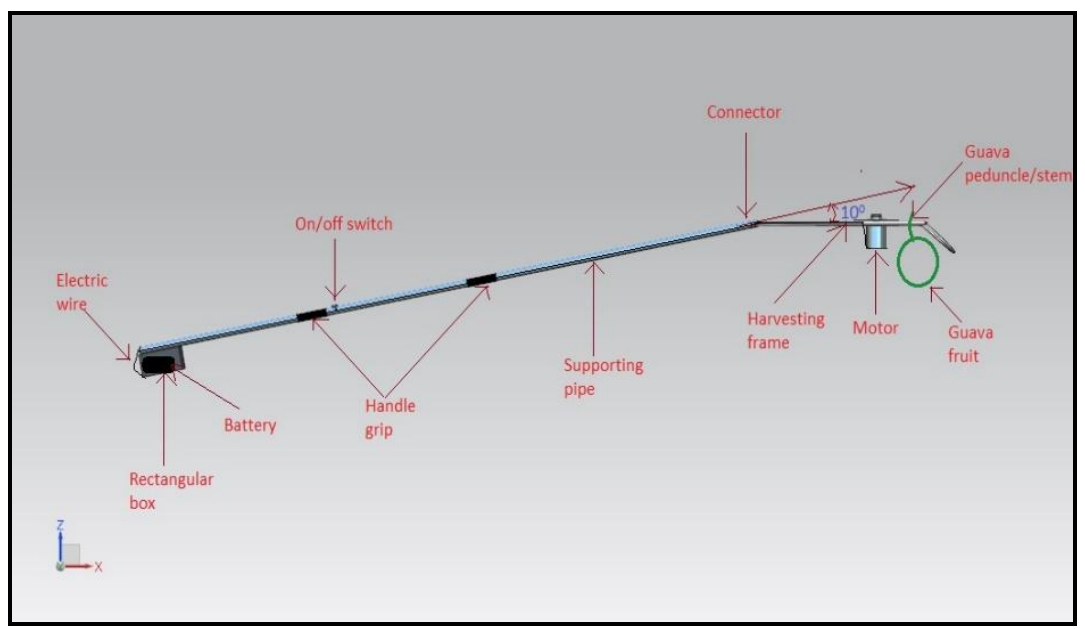


Fig.4 Side view of the developed harvesting device

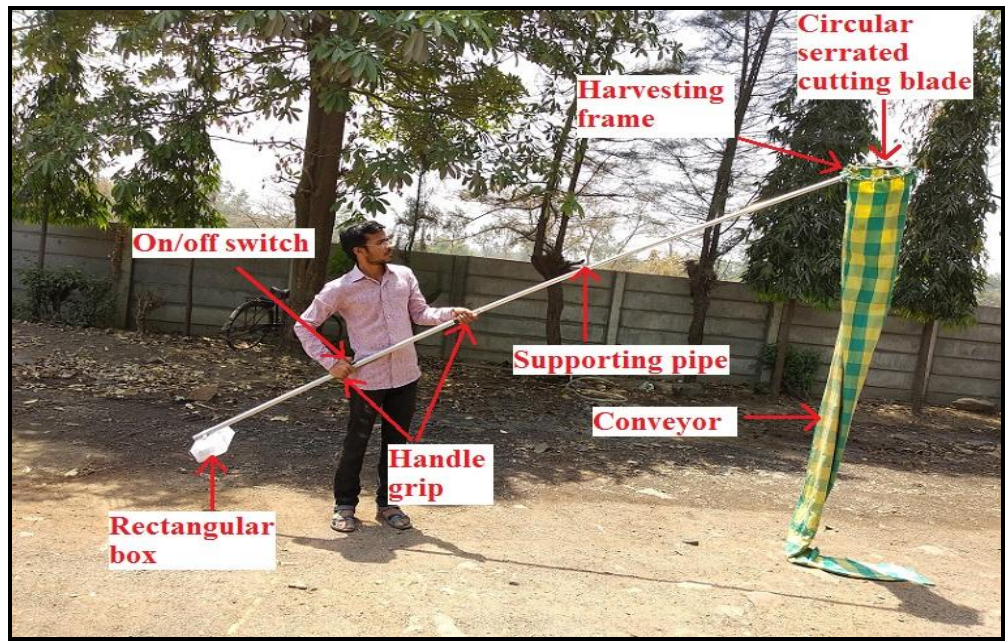

Fig.5 Conceptual view of the drawing of the developed harvesting device

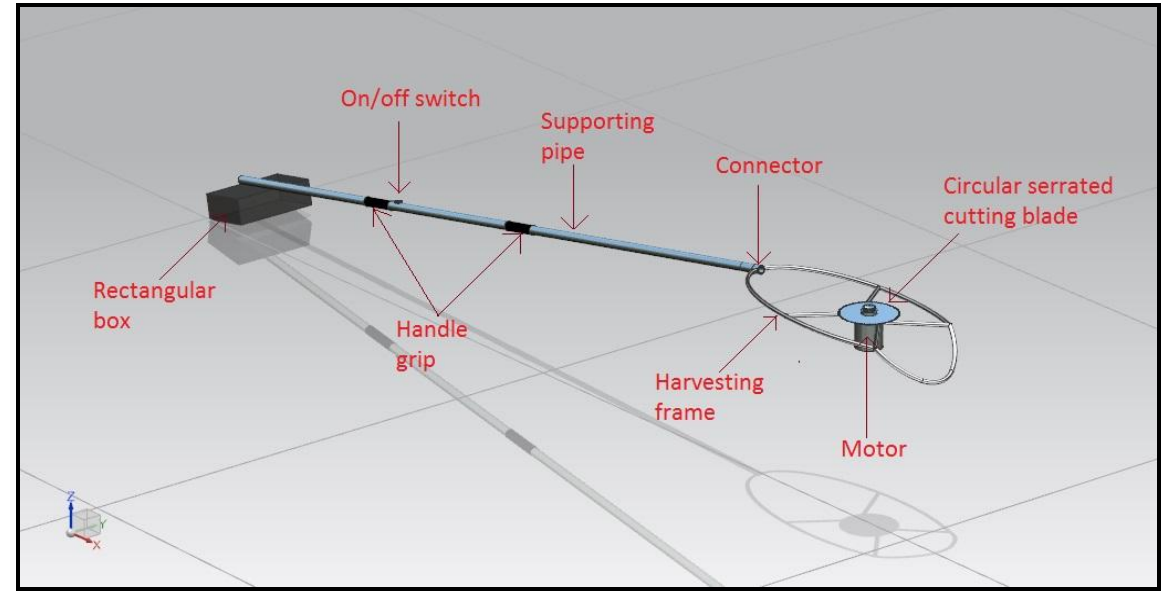

Fig.6 A view of the developed harvesting device

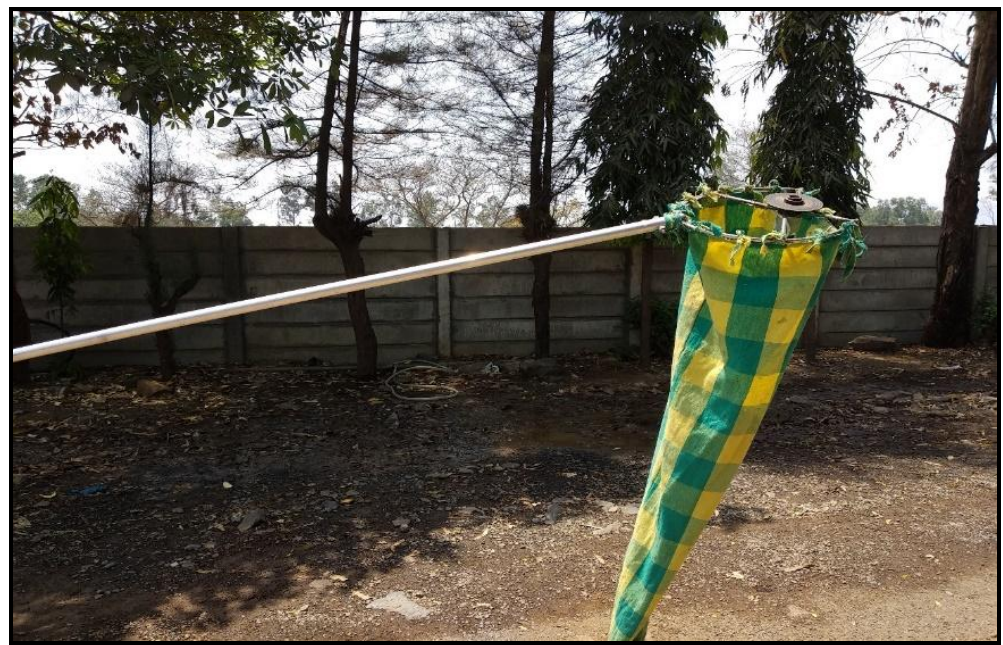


Fig.7 Fruit cutting at $360^{\circ}$ around periphery of cutting blade

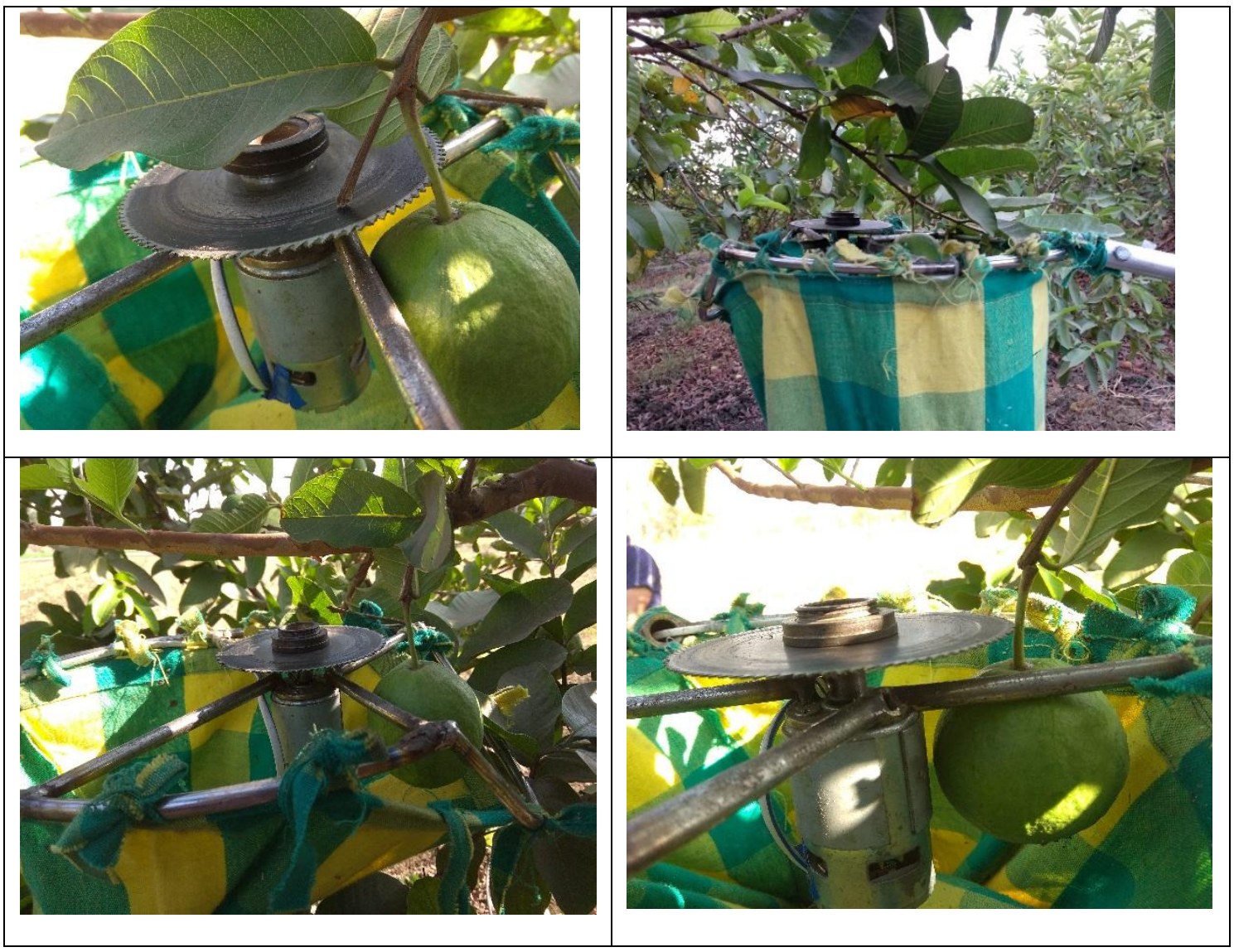

Fig.8 Front view of the drawing of harvesting frame

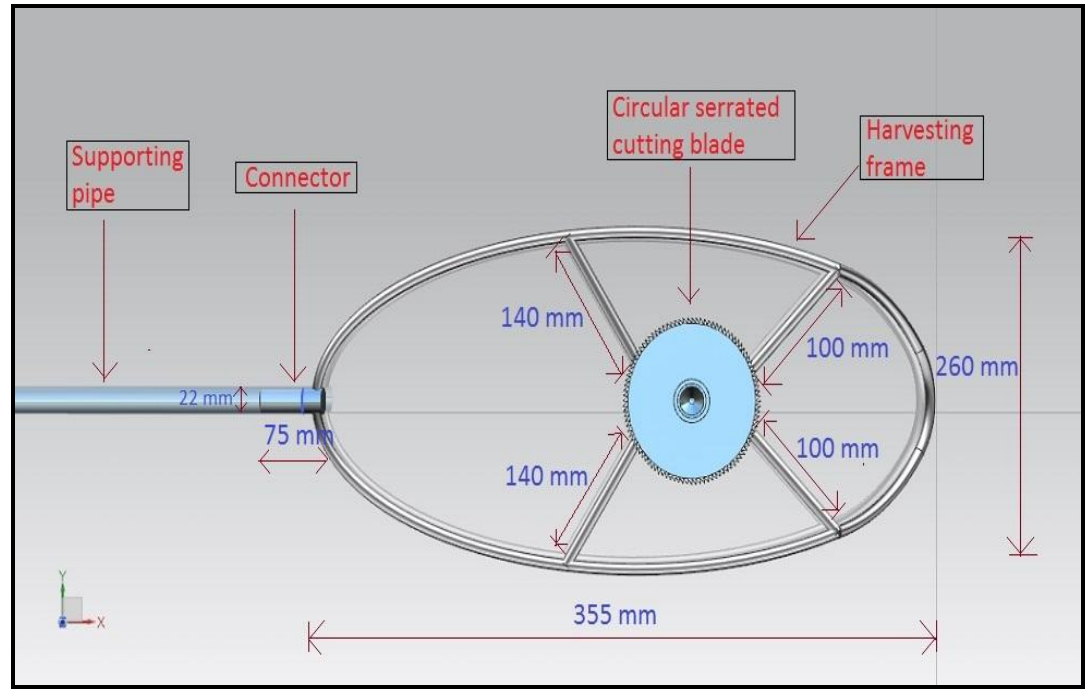


Fig.9 Side view of the drawing of harvesting frame

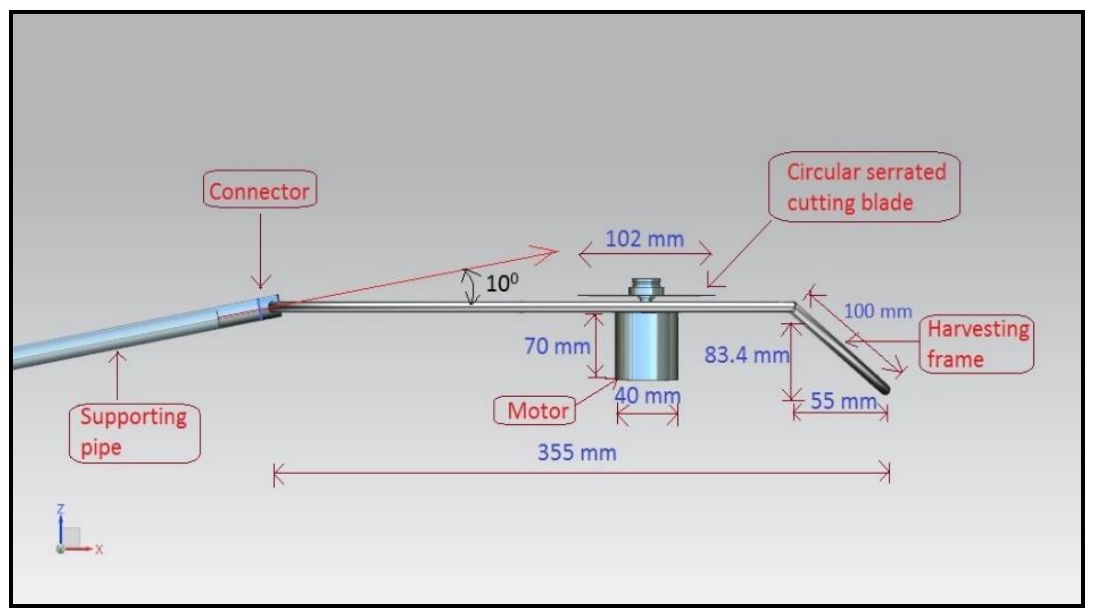

Fig.10 Front view and side view of harvesting frame

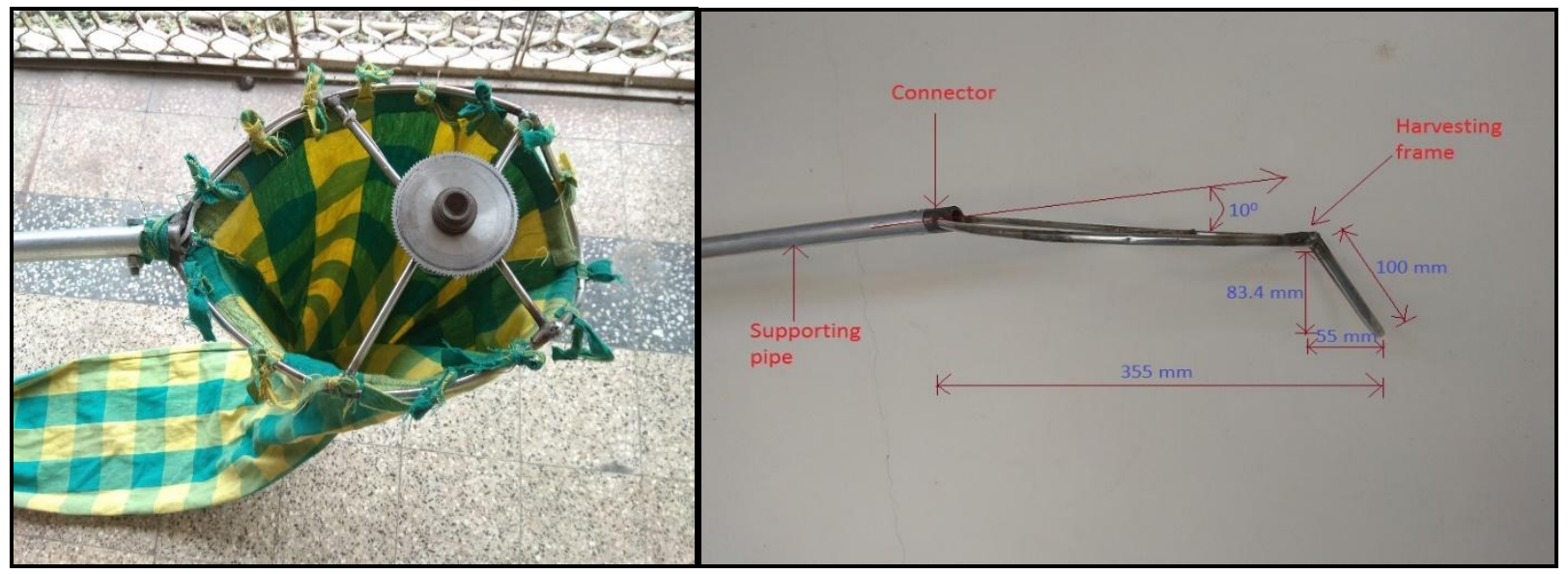

Fig.11 (A) A view of full length supporting pipe (B) Two different length and same diameter supporting pipe

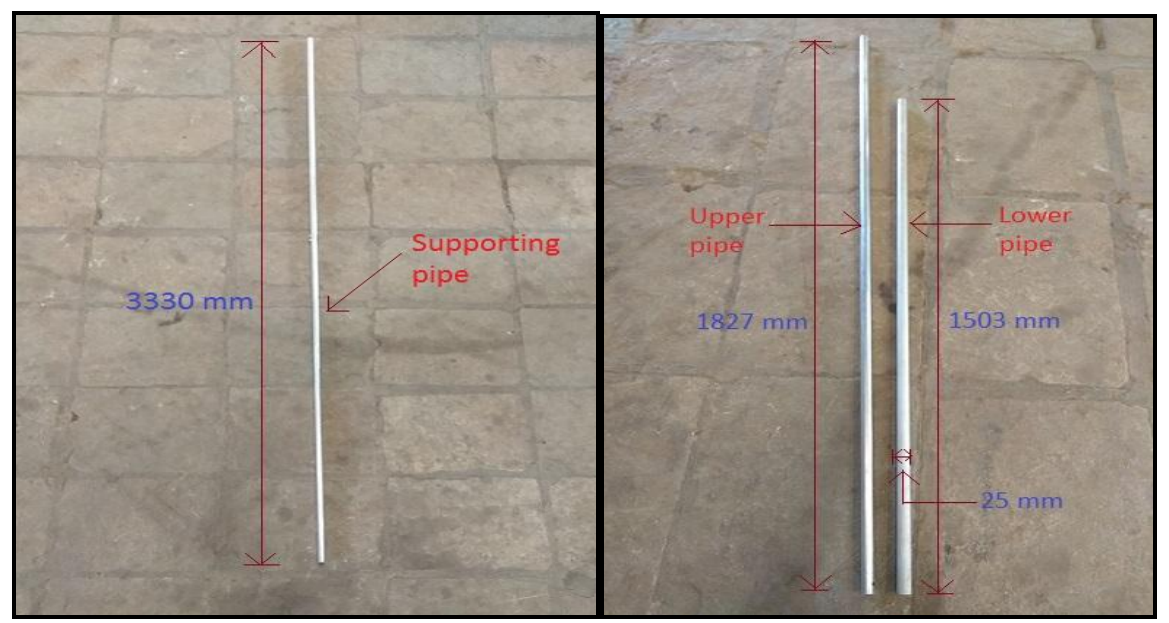

(A)

(B) 
Fig.12 (A) A view of jointer (B) A view of connector

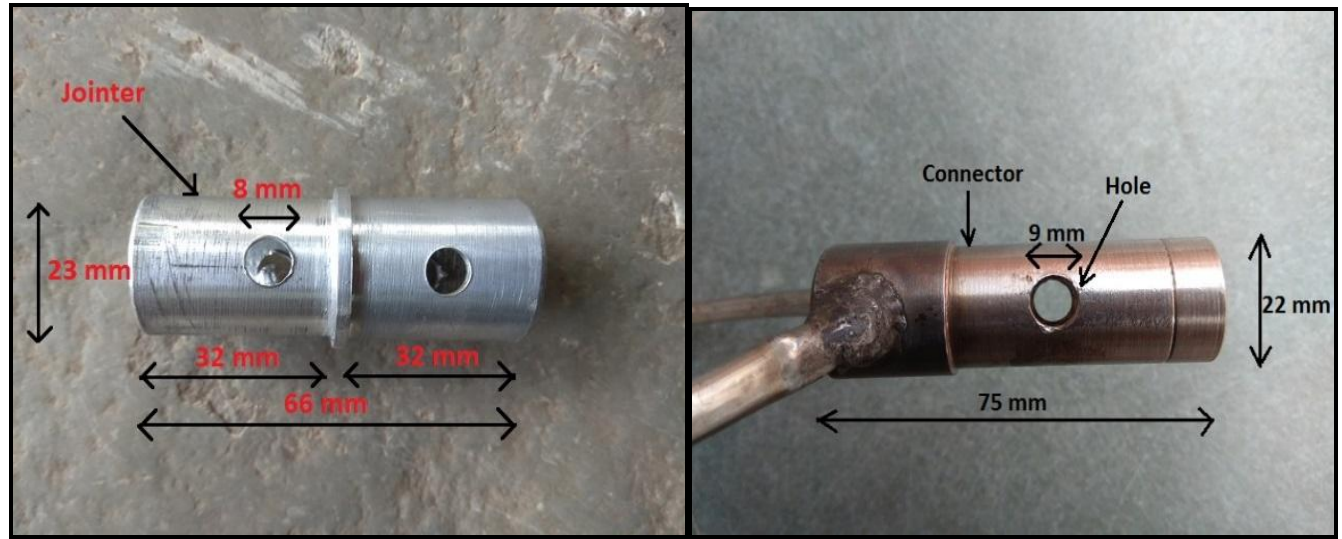

(A)

(B)

Fig.13 A view of circular serrated cutting blade

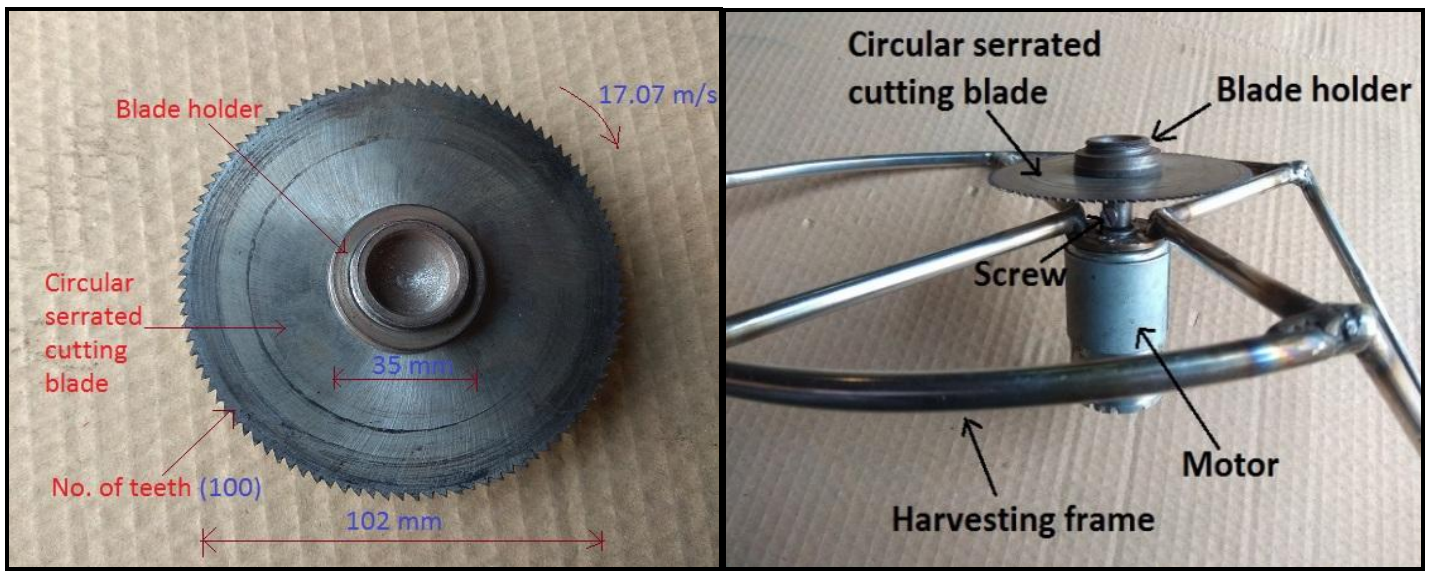

Fig.14 A view of DC motor

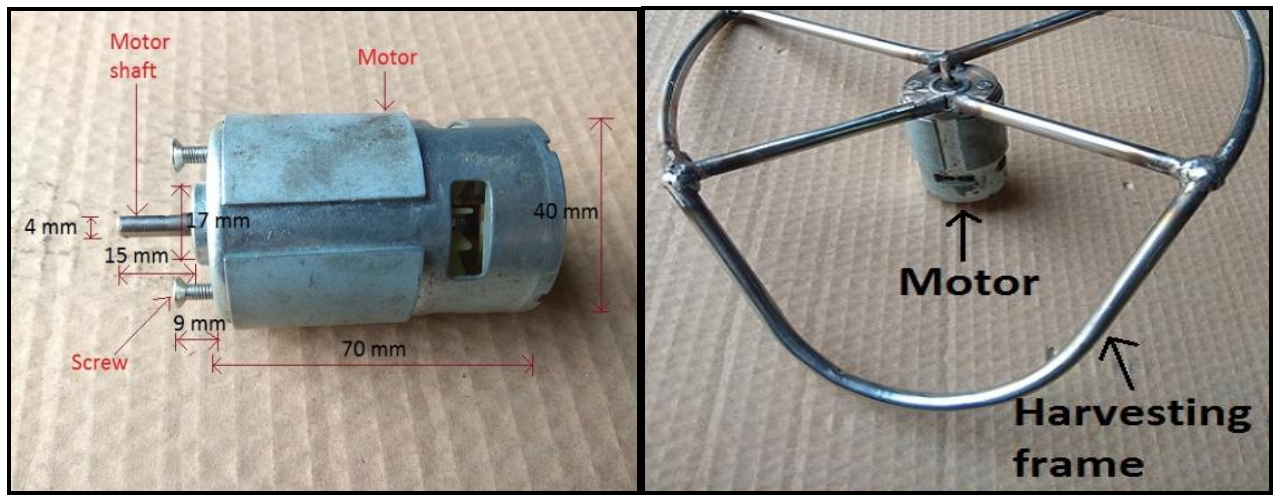


Fig.15 Measurement of speed of motor with load rating

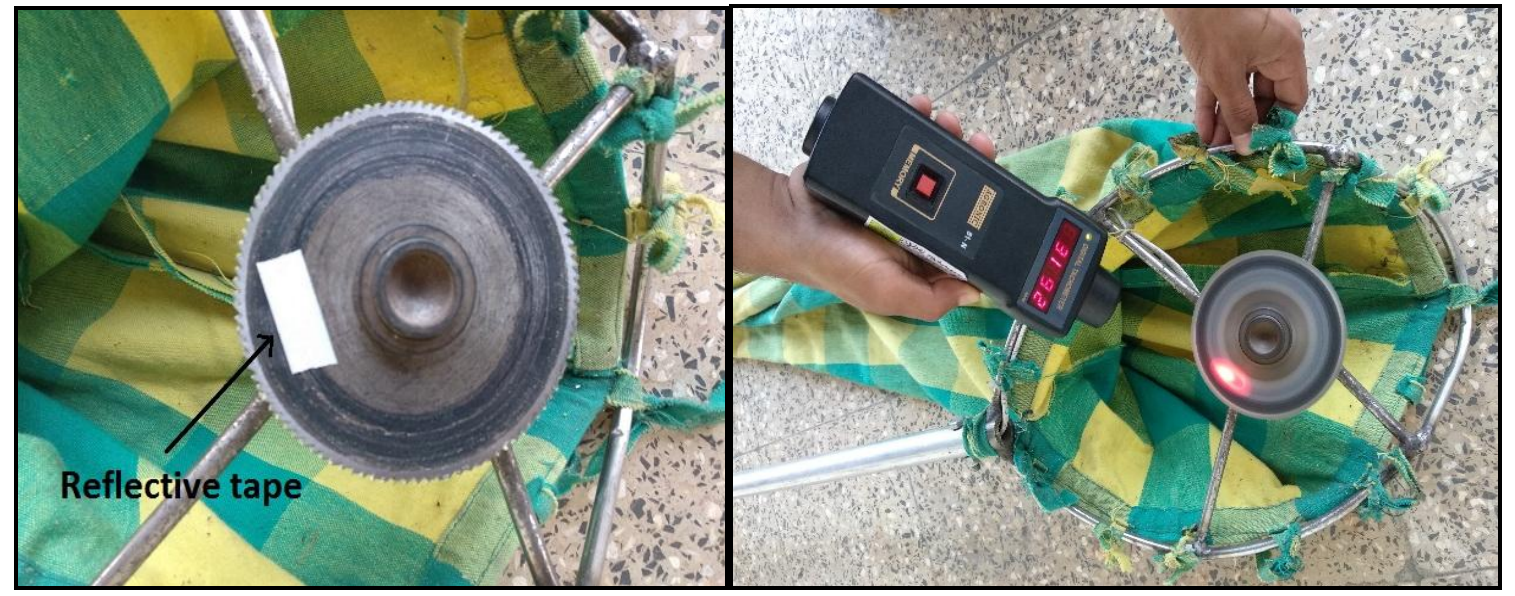

Fig.16 A view of sealed lead acid battery

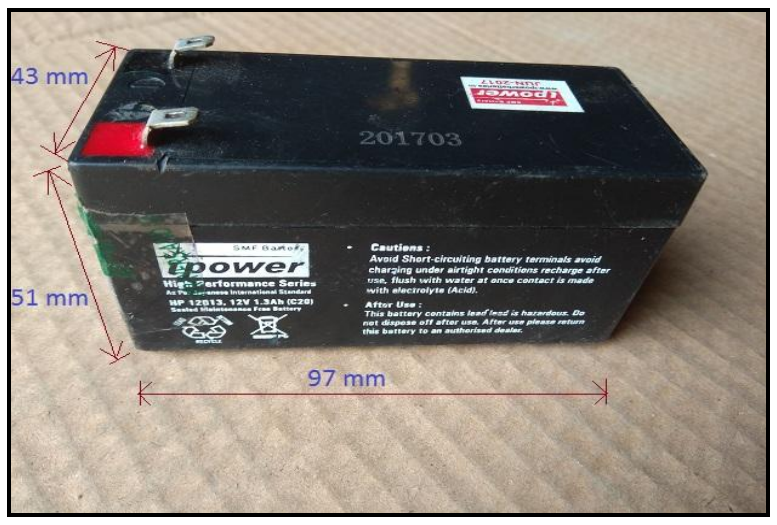

Fig.17 Location of on/off switch

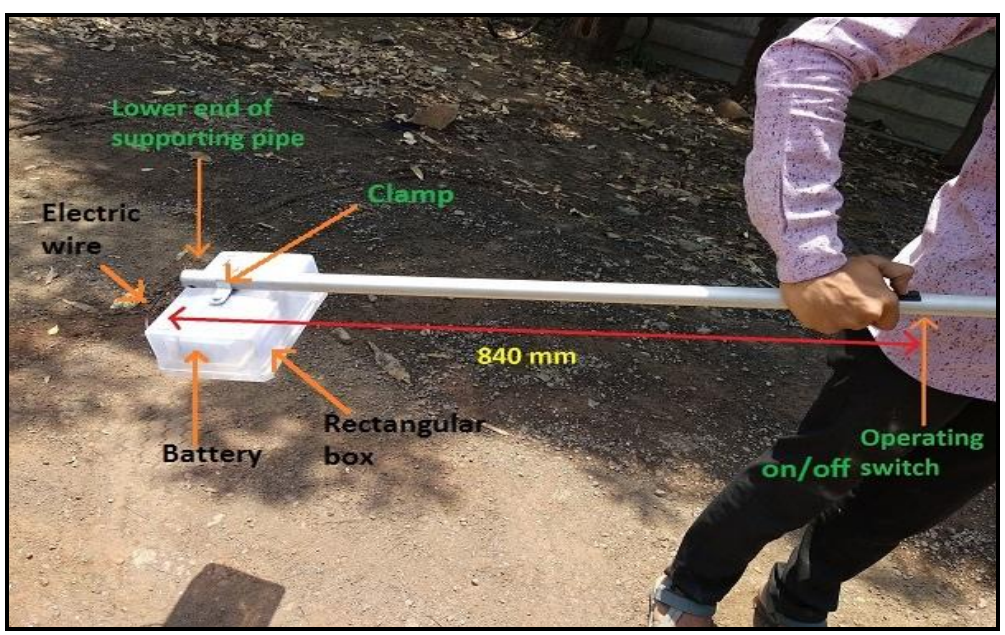


Fig.18 Schematic view of the design of handle grip, on/off operating switch and rectangular box

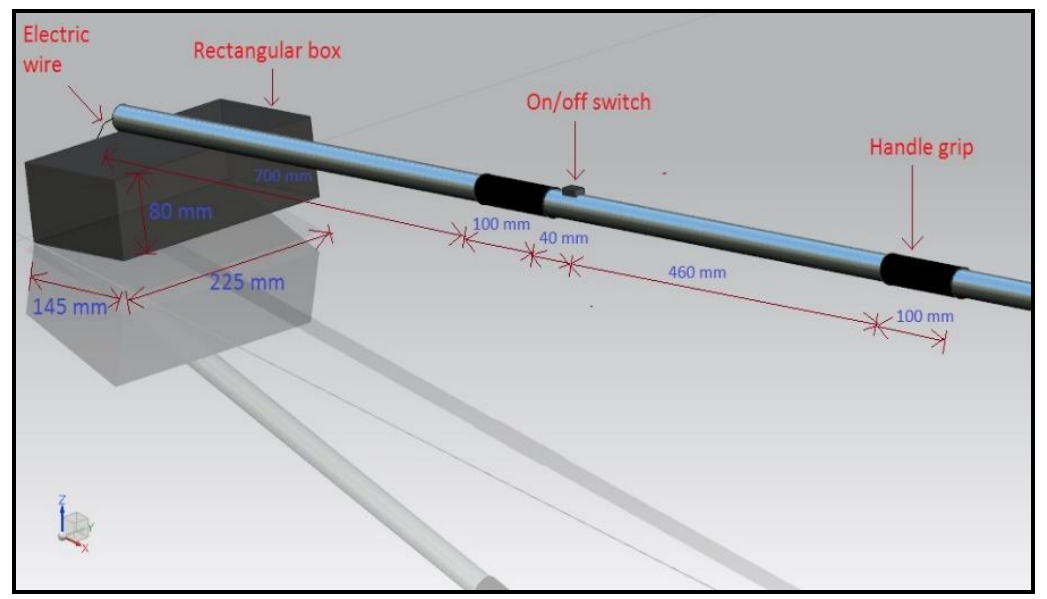

\section{Battery}

Battery is the stored energy device was used to operate the mechanism. $12 \mathrm{~V}, 1.3 \mathrm{Ah}$ sealed lead acid battery was used to operate motor (Fig. 16). Battery was put into the rectangular box and rectangular box was fitted at the lower end of supporting pipe by means of clamp. This is the advantage over the balance of harvesting device with the help of adding weight of battery and rectangular box at lower level of supporting pipe.

\section{Location of on/off operating switch and rectangular box}

On/off operating switch was fitted between two handle grips at lower pipe $40 \mathrm{~mm}$ distance from lower handle grip. For easy operation, it was located near the lower handle grip. Distance between switch and lower end of supporting pipe was kept 840 $\mathrm{mm}$ as shown in Figure 17.

A rectangular plastic box was used to hold the battery and attached at the lower end of the supporting pipe. If additional weight is required to balance the device, the rectangular box may be filled with additional weight along with battery. Schematic view of the design of handle grip, on/off operating switch and rectangular box is shown in Figure 18.

\section{Weight distribution of the developed harvesting device}

Harvesting device should be light in weight for easy to operate and handle it while harvesting of guava fruits. Hence lightweight materials were used for fabrication of the device. The device was balanced for ease of operation by weight distribution into three different portions which is described in Table 1. Specifications of each parts of the device are described in Table 2.

\section{Overview of the developed harvesting device for guava fruit}

This device was operated by on/off operating switch so that makes it easy to operate. Conveyor was used for fruit conveying from harvesting frame to fruit collecting bucket. Harvesting frame was fabricated in such a way that guava fruits being cut an around $360^{\circ}$ angle around its periphery of harvesting frame. $10^{\circ}$ angle between harvesting frame and supporting pipe was kept for proper alignment of cutting mechanism with stem or peduncle of guava fruit. Two aluminum pipes were used for easy transportation and ease of assemble and dissemble. The device was balanced by weight distribution into three different portions that provide cease at the time of working. 


\section{References}

Anonymous. 1994. Development and testing of "Nutan" mango harvesting device. Dr. Balasaheb Sawant Konkan Krishi Vidhyapeeth, Dapoli, Maharastra, http://www.dbskkv.org/Research/ Implements and Machinery. html, Accessed on 4 October 2017.

Anonymous. 1996. Design and development of an improved mango harvester. Indian Agricultural Research Institute, Delhi, www.iari.res.in/files/Books/Fundament al $\% 20$ of $\% 20$ Fruit $\% 20$ production.pdf, Accessed on 4 October 2017.

Hamam, A. S., El-Iraqi, M. E., Sharibim, Y. and Awais, T. R. 2011. Design and evaluation of mechanical picking heads for citrus fruits harvesting. Egypt. J. Agril. Res. 89(4):1545-1560.

HSD. 2017. Horticultural statistics at a glance. Horticultural Statistics Division, Department of agril. Co-operation and farmers welfare, Ministry of agriculture and farmers welfare, GOI, pp 155-156,
http://nhb.gov.in/statistics/Publication/H orticulture $\% 20 \mathrm{At} \% 20 \mathrm{a} \% 20$ Glance $\% 20$ 2017\%20for\%20net\%20uplod\%20(2).P df, Accessed on 10 May 2018.

Nakum, D. A., Rabadiya, D. J. and Vaghasiya, S. M. 2018. Design and development of battery operated mango harvester. Unpublished thesis, Department of Farm Machinery and Power Engineering, Junagadh Agricultural University, Junagadh.

Siwalak, P.; Sriwai, S. and Thongchai, K. 1989. Developed a hand held and operated single fruit harvesting device and a mango stem picker. Thai Agriculture Research Journal (Thailand), 7(1-3): 69-78.

Valdez, J. A. 1999. Developed a fruit harvester to minimize the damage and ease mango harvesting operation. Philipine Council for Agricultural, Forestry and Natural Resources, Research and Development, Los Bonos. pp 22-33.

\section{How to cite this article:}

Matholiya, C.S., A.L. Vadher, S.K. Jain, Nayaka, M.J. 2019. Development of Battery Powered Manually Operated Device for Guava Harvesting. Int.J.Curr.Microbiol.App.Sci. 8(01): 625640. doi: https://doi.org/10.20546/ijcmas.2019.801.070 